\title{
A representação da mônada: expressão e ideias inatas em Leibniz ${ }^{1}$
}

Representation in the monad.

Expression and innate ideas in Leibniz

Sacha Zilber Kontic

Universidade de São Paulo

\section{RESUMO}

Trata-se de analisar o conceito leibniziano de ideia expressiva a partir da noção de expressão como uma relação de ordem entre dois ou mais elementos distintos para demonstrar como, com ela, Leibniz constrói uma crítica à concepção da representação na percepção como imitação ou cópia de um original. Buscamos assim entender em qual sentido a defesa de uma concepção inatista das ideias permite com que o autor alemão considere que tanto Descartes quanto Locke sejam vítimas do mesmo erro em relação às suas noções de percepção.

\section{PALAVRAS-CHAVE}

Leibniz, Percepção, Representação, Ideias, Inatismo.

\begin{abstract}
Our intention is to analyze the leibnizian concept of expressive idea through his notion of expression as relation of order between two or more distinct elements to demonstrate how Leibniz constructs with it a critic to the conception of perceptive representation as an imitation or copy of an original. We aim to understand with this in which sense the defense of an inatist conception of ideas allows the German author to consider that both Descartes and Locke are victims of the same error concerning their accounts of perception.
\end{abstract}

\section{KEY WORDS}

Leibniz, Perception, Representation, Ideas, Inatism.

\footnotetext{
I O presente artigo é uma versão modificada do primeiro capítulo da minha dissertação de mestrado, defendida na Universidade de São Paulo (USP) sob orientação da Professora Tessa de Moura Lacerda. Em sua realização, contei com bolsa do cNpq.
} 
A mônada, diz Leibniz, é um "espelho vivo do universo". Por ser simples, ela representa a multiplicidade presente no universo, a partir de sua própria atividade perceptiva. Entretanto, que tipo de representação é gerado por esse espelho que, por não ter portas nem janelas, não pode refletir nenhum objeto exterior? Em um opúsculo de 1676 , o autor explica o sentido da metáfora:

Não se deve pensar que, quando falo em espelho, me aproximo da opinião de que as coisas externas são constantemente retratadas nos órgãos e na própria alma. Para a expressão de uma coisa em outra, é suficiente que exista uma lei constante de relações pelas quais os elementos singulares da primeira possam ser relacionados aos elementos singulares que correspondem a eles na segunda. (c, p. 15)

Portanto, se a Mônada é um espelho, não é porque reproduz em si mesma o reflexo de algo que está fora dela. É um espelho do universo porque expressa, a partir de si mesma, o objeto nela representado. A representação é então essa lei constante de relações, presente na expressão de uma coisa em outra. Mas, então, o que é a ideia, entendida como a representação de um objeto na mente, se não o reflexo ou imagem de algo exterior?

\section{A representação expressiva}

Leibniz, assim como Descartes, concebe as ideias como o conteúdo do pensamento. Contudo, o sentido que atribui ao seu caráter representativo aponta para uma ruptura radical com o cartesianismo. Ao mesmo tempo em que se coloca em certa continuidade com Descartes, na medida em que assume que a ideia é a representação de algo em nossa mente, Leibniz se opõe à definição cartesiana de ideia, ao apontar para a insuficiência da imitação como a única classe possível de ideias. A exemplo de Descartes, Leibniz toma a ideia como o conteúdo imediato de nosso conhecimento intelectual ou sensível, que é próprio do espírito. Mas, por considerar a ideia como o objeto do pensamento, e não como sua forma, pode afirmar que a ideia não precisa estar atualmente na consciência para ser representativa. A ideia é inata à alma humana, seja pensada ou não, e vem ao pensamento quando é atualizada. Também por isso, o Discurso de metafísica

2 Para as citações das obras de Leibniz, adotamos a notação consagrada: c: Opuscules et fragments inédits de Leibniz (Couturat, L. ed.), GP: Die philosophischen Schriften von G. W. Leibniz. (Herausgegeben von C. I. Gerhardt), A: Sämtliche Schriften und Briefe (Herausgegeben von der Berlin Brandenburgischen Akademie der Wissenschaften und der Akademie der Wissenschaften in Göttingen). 
considera adequado distinguir as ideias das noções, por mais que não haja uma diferença de natureza entre elas, no que se refere ao caráter representativo: "podem denominar-se ideias essas expressões, concebidas ou não, existentes em nossa alma; já as que se concebem ou são formadas podem denominar-se noçôes, conceptus" (Id., A VI, 4, p. I572). Por serem objeto do pensamento, as ideias estão em nossa alma, quer as atualizemos ou não, existem em nós mesmo fora do campo restrito da consciência, como que inscritas no fundo do espírito.

Mas a alma não se abre à leitura tal como a ideia-quadro de Descartes, não basta um ato de vontade para que nos voltemos à ideia. Em oposição à passividade inerente da ideia-quadro, Leibniz afirma a atividade expressiva da ideia. A ideia é a faculdade de pensar em um objeto quando a ocasião para isso se apresenta; como se afirma no opúsculo Quid sit idea, de $\mathrm{i} 678$, ela "não consiste em algum ato de pensar, mas sim na faculdade de exercê-lo, e afirmamos que temos a ideia da coisa, embora nela não pensemos, desde que possamos, dado o caso, pensar ao seu respeito" (Id., A vI, 4, p. I370). Ora, se a ideia é uma atividade expressiva, cabe-nos considerar o que Leibniz entende, mais exatamente, por expressão, em que sentido este conceito se torna central para compreender o caráter representativo da ideia, e, por fim, a mudança que isso significa em relação ao cartesianismo.

Neste mesmo opúsculo, Leibniz define a expressão nos seguintes termos: "dizemos que exprime uma coisa aquilo em que existem os modos correspondentes aos modos da coisa a ser expressa" (Ibid.). Esta relação é então uma relação de correspondência entre o que exprime e o que é expresso. Ela, porém, não tem necessariamente apenas um sentido, do que exprime ao que é exprimido: essa relação pode ser também recíproca. Entre os polos da expressão, a relação não é de prioridade ou anterioridade, é biunívoca. Entre a equação e o círculo, podemos dizer tanto que a equação expressa o círculo quanto que o círculo expressa a equação. Não há um sentido único da expressão; toda a correspondência é, em última análise, recíproca.

Para haver expressão, é necessário haver um elemento invariante qualquer, que garanta a correspondência mútua entre as relaçôes. O que liga os diversos elementos da relação expressiva (a máquina e o módulo, a projeção plana e o sólido, a figura e a equação, etc.) é uma invariância no interior dessas relações, algo que permanece na totalidade das variações. Se, entre os polos da expressão, todos os elementos são conservados, há entre eles uma perfeita identidade. Se, ao contrário, a variação dos elementos é máxima, temos a diferença. Mas, como alerta Michel Serres, devemos estar atentos aos dois sentidos que Leibniz atribui à palavra variação: "de um lado, a analogia é uma invariância de alguma forma e identidade, a totalidade das invariâncias; de outro, esse algo de análogo pode 
variar (relação, ponto, direção...), tornar-se tudo (identidade) ou nada (diferença absoluta)" (Serres 200I, p. 59). Não há, na relação expressiva, nem perfeita identidade, na qual não há absolutamente variação de nenhum elemento, por menor que seja, nem perfeita diferença, onde nenhum dos elementos é conservado, por menor que seja. É em virtude disso que Leibniz pode elaborar a máxima: "todo efeito integral representa sua causa plena", na medida em que, entre a causa e o efeito, algo é conservado, e, pelas leis das relaçôes expressivas, podemos conhecer no efeito aquilo que corresponde a sua causa.

É assim que Leibniz afirma que nossa alma expressa todo o universo, pois, sendo criada por Deus, ela o expressa, e, ao expressá-lo, expressa também todo o universo por ele criado, bem como todos os possíveis não existentes, que estão na mente divina. Por isso, podemos dizer que temos todas as ideias inscritas em nossa alma por Deus, embora não possamos conceber todas elas distintamente. $\mathrm{O} \$ 26$ do Discurso de Metafisica é esclarecedor a respeito. Como já vimos, ao definir a ideia como objeto, não como forma do pensamento, podemos afastar a noção de que só temos a ideia no espírito quando a pensamos. Sendo objeto, a ideia persiste na alma mesmo quando não a contemplamos. Assim,

Nossa alma tem sempre em si mesma a qualidade de representar qualquer natureza ou forma, seja qual for, quando quer que surja a ocasião de pensar nela. E, desde que expresse qualquer natureza, forma ou essência, julgo ser esta qualidade da nossa alma propriamente a ideia da coisa, existente em nós e sempre em nós, quer pensemos nela ou não (Leibniz A VI, 4, p. I570).

Portanto, não faz sentido afirmar que algo vindo do exterior pode penetrar em nossa alma. Ela não possui portas ou janelas por onde as coisas podem entrar ou sair. Todos os nossos pensamentos passados, presentes e futuros já estão em nossa alma desde a criação, e não temos nenhuma ideia que já não estava anteriormente em nosso espírito.

A relação da temática da expressão com a teoria da percepção leibniziana é explicitada pelo filósofo a partir de uma indagação de Arnauld em uma carta de I687. Nela, ao ser questionado sobre o que é a expressão, Leibniz a define nos seguintes termos: "Uma coisa exprime uma outra (nos meus termos) quando há uma relação constante e regrada entre o que se pode dizer de uma e de outra" (Id., A II, 2, p. 22I, pp. 240-24I). A expressão, portanto, é colocada aqui como uma relação de lei ou de ordem entre o que exprime e o que é exprimido. O que ocorre com um dos elementos da expressão também deve ocorrer com o outro, sem a necessidade de uma relação de causalidade. É necessário apenas que se mantenha 
uma mínima analogia entre o que se pode dizer de ambos. E, assim, através desta analogia, mantém-se a lei ou regra, ou seja, um elemento invariante, entre os diferentes polos da expressão. Cada elemento opera segundo suas próprias leis, e a analogia garante a correspondência recíproca das relaçôes. O fundamental é que haja uma lei das variações, e não uma semelhança evidente entre dois elementos quaisquer. Se há uma relação de ordem entre ambos os polos da relação expressiva, não é necessário que entre eles haja uma imagem em comum.

A essa definição de expressão, Leibniz acrescenta ainda na mesma carta:

A expressão é comum a todas as formas, e é um gênero do qual a percepção natural, a sensação (sentimento) animal e o conhecimento intelectual são espécies. Na percepção natural e na sensação, basta que o que é divisível e material, e se encontra disperso em diversos seres, seja exprimido ou representado em um único ser indivisível, seja na substância que é dotada de verdadeira unidade. Não se pode duvidar da possibilidade de tal representação de várias coisas em uma só, pois nossa alma nos fornece um exemplo disto. Essa representação é acompanhada de consciência na alma racional; a isso damos o nome de pensamento. (Ibid., p. 24I)

Ao colocar a percepção, assim como o pensamento, como espécies do gênero expressão, Leibniz atribui à atividade expressiva todos os graus de percepção, sensível ou intelectual. Essa caracterização da percepção a coloca como uma relação expressiva que se vale do modelo um-múltiplo, segundo a caracterização que fizemos anteriormente. ${ }^{3}$ Nela, a multiplicidade das representações é expressa na unidade da substância simples ou mônada (e, vale destacar aqui, mesmo as mônadas brutas são dotadas de uma espécie de percepção obscura).

Desse modo, a percepção, por ser um modo da expressão, prescinde, rigorosamente falando, de uma relação de imitação ou de cópia entre a coisa percebida e a representação que formamos dela, assim como em todas as relações expressivas a percepção mantém uma relação regrada com aquilo que ela exprime independentemente de haver ou não uma imagem em comum. A mesma coisa pode ser representada de modos diversos, desde que a relação de ordem entre as diversas representações se mantenha.

Representar deixa de ser para Leibniz a simples apresentação de uma coisa ao intelecto, como defendem Descartes e os cartesianos. Possuir a ideia de algo

3 Essa caracterização é retomada de modo semelhante no $\$$ I4 da Monadologia, onde Leibniz define a percepção como "o estado passageiro que engloba e representa uma multiplicidade na unidade ou na substância simples" (Id., GP VI, p. 6o8). 
não é mais possuir a coisa mesma enquanto um conteúdo do intelecto, ou seja, enquanto uma ideia-quadro passiva, para qual o intelecto se volta ao pensar, mas antes o estabelecimento de uma ordem ou lei das relaçôes, que permanece a mesma por mais variações que se coloquem. Podemos dizer assim, sem medo de abusar da palavra, que a equação é uma representação da figura geométrica, que o círculo é uma representação da parábola, que o discurso é uma representação do pensamento, que um desenho plano representa uma máquina, do mesmo modo que uma ideia representa um ideado.

Ora, se as ideias são para Leibniz expressões das coisas e não uma representação sui generis, como pretende Descartes, não faz sentido restringi-las a uma classe essencialmente diferente de representação, ou seja, não é necessário que elas possuam uma realidade objetiva no intelecto que as diferencie dos outros modos de representação. ${ }^{4} \mathrm{O}$ que torna as ideias um tipo de representação específico não é ser mais representação, ou ainda de ser uma representação mais fiel, mas sim representar uma dada multiplicidade na unidade da alma. A representação, compreendida como expressão, permite que essa semelhança intuitiva que Descartes exige para haver ideia deixe de ser a norma para se tornar um caso-limite. A semelhança se aproxima da perfeita identidade, na medida em que a variação entre os polos da expressão se aproxima do mínimo, e, quanto mais dele se afasta, mais obscura ela se torna.

\section{Expressão e inatismo}

Leibniz defende, como Descartes, que temos em nós todas as nossas ideias. Contudo, ele abandona a semelhança intuitiva como critério para avaliar a realidade objetiva das ideias. Se a ideia é expressão, ela é representativa por sua própria natureza, por mais que não haja semelhança imediata entre a representação e a coisa representada. O inatismo leibniziano é, portanto, diferente do inatismo cartesiano. Se o último se fundamenta na disposição do espírito de se representar adequadamente a essência das coisas a partir de noções inatas ao nosso espírito, a construção leibniziana das ideias inatas deverá tomar como ponto de partida a

4 Como explica Descartes na resposta às primeiras objeções, dizer que a ideia está objetivamente no intelecto "não significa nada além de que a coisa existe no intelecto da maneira que as coisas costumam nele existir. Assim, por exemplo, se alguém perguntasse o que acontece com o sol pelo fato dele existir objetivamente em meu intelecto, a melhor resposta seria que nada acontece com ele senão uma denominação extrínseca, a saber, que o sol encerra a operação do intelecto ao modo de um objeto. Mas se alguém perguntasse o que é a ideia do sol, e a resposta fosse que é a coisa pensada, enquanto ela está objetivamente no entendimento, ninguém a tomaria como sendo o sol enquanto que essa denominação extrínseca está nele” (Descartes I97I, vol. viI, p. IO2/ vol. IX, pp. 8I-82). 
qualidade da alma de representar as coisas segundo as relações expressivas que ela estabelece com o universo. Por isso que, no já citado $\$ 26$ do Discurso de Metafisica, Leibniz pode afirmar que a alma não possui portas ou janelas por onde as coisas possam entrar, mas sim as regras das relações expressivas que ela trava com Deus e com o universo. Vejamos esse item com mais atenção:

Para bem conceber o que é a ideia, é necessário precaver-se contra um equívoco, pois muitos tomam a ideia como a forma ou diferença de nossos pensamentos. Dessa maneira, só teríamos a ideia no espírito enquanto pensamos nela, e, todas as vezes que pensamos nela novamente, teríamos ideias diferentes das mesmas coisas, embora semelhantes às ideias precedentes. Outros homens, ao que parece, tomam a ideia como um objeto imediato do pensamento ou como uma outra forma duradoura que permanece quando não a contemplamos mais. De fato, nossa alma possui sempre, em si mesma, a qualidade de se representar alguma natureza ou forma qualquer, sempre que houver ocasião para tanto. Ora, creio que essa qualidade de nossa alma, enquanto ela exprime alguma natureza, forma ou essência, é propriamente a ideia da coisa, que é em nós e que está sempre em nós quer pensemos nela ou não (Id., A VI, 4, p. I570. Itálicos nossos).

Nessa passagem, Leibniz identifica duas concepções de ideia, ambas de alguma forma devedoras de Descartes, que se opõem quanto à forma de conceber o inatismo das ideias. Pela primeira - posição de Foucher e, em menor grau, de Arnauld - a ideia, sendo forma do pensamento, nasce pela ação da alma quando pensamos em algo e cessa de existir quando deixamos de pensar nela. Quando temos novamente a ideia de algo em que já pensamos, temos uma nova ideia da mesma coisa, que é semelhante à anterior, mas, mesmo assim, distinta dela, por ser a forma de um novo pensamento. Segundo essa concepção, dizer que as ideias são inatas não significa dizer que elas existem em nós mesmo antes de pensarmos nelas, mas antes, que nossa alma pode formá-las, como diz Descartes, a partir de si mesma, sem a necessidade de uma relação causal entre um objeto exterior e o intelecto.

A segunda concepção apontada por Leibniz atribui à ideia um caráter permanente, de modo que não é necessário que a ideia seja pensada para que ela exista. Dissociando-se a ideia do ato de pensar, ela passa a ser algo permanente, que se torna objeto ou forma do pensamento a partir do momento em que se dá a ocasião para ela ser pensada. Essa posição não implica necessariamente em uma concepção inatista das ideias. Malebranche, por exemplo, a quem Leibniz indiretamente se refere nessa passagem, considera que as ideias são objetos permanentes 
existentes na mente divina, mas que não podem ser criados pela própria alma. Assim, quando dizemos que possuímos uma ideia, dizemos que vemos essa ideia em Deus, mas não a possuímos em nós como uma ideia inata.

Afastando desses dois equívocos, Leibniz afirma que a ideia, por ser expressiva, está em nós e permanece em nós quer pensemos nela ou não. Já vimos que a ideia pode estar composta em um conhecimento sem que tenhamos necessariamente consciência dela. Mas aqui Leibniz apresenta a versão mais forte desse argumento: não só podemos ter ideias sem que nos apercebamos delas, como possuímos sempre e permanentemente as nossas ideias em nossa alma. Criada por Deus, a alma o expressa, tal como o efeito expressa sua causa, pois contém a regra ou relação que exprime a relação que mantém com sua causa ou, como vimos, todo efeito integral corresponde a sua causa plena. E, expressando Deus, a alma expressa todo o universo por ele criado. Ora, se a ideia é, como afirma essa passagem do Discurso, "essa qualidade da alma enquanto ela exprime alguma natureza, forma ou essência" (Ibid., p. 1570), ao expressar Deus e o universo, a alma exprime todas as formas e essências existentes no intelecto divino, e, portanto, possui a ideia de todas as coisas de forma inata no espírito:

Temos essas formas no espírito, e as temos desde sempre, pois o espírito exprime sempre todos os seus pensamentos confusos, e já pensa confusamente em tudo o que um dia pensará distintamente. Nada poderia nos ser ensinado cuja ideia não tenhamos já no espírito, pois essa ideia é como a matéria de que se forma esse pensamento. (Ibid., p. I57I)

Assim, a versão leibniziana do argumento das ideias inatas não significa somente que temos em nós a disposição de despertar ideias inatas quando a ocasião se oferece, mas, sobretudo, que possuímos atualmente em nossa mente a totalidade de nossas ideias - que por sua vez expressam a totalidade do universo — , embora só pensemos nessa totalidade confusamente. $\mathrm{O}$ argumento de Leibniz em prol das ideias inatas se configura desse modo como uma posição muito mais radical do que a cartesiana. Temos em nós ideias da totalidade da mente divina, umas mais distintas e outras percebidas apenas confusamente, conforme a ocasião para pensá-las de um modo ou de outro se apresenta. A crítica à noção cartesiana de ideia se aprofunda: não é necessário separar o componente passivo do pensamento (a ideia-quadro) de seu componente ativo (o julgamento). Para Leibniz, as ideias são sempre ativas na medida em que expressam, distinta ou confusamente, as coisas por elas representadas.

É nesse ponto que a crítica de Leibniz ao cartesianismo encontra sua crítica ao empirismo de Locke. Nos Novos Ensaios, a crítica feita pelo leibniziano Teófilo 
à noção da tabula rasa, tal como exposta pelo lockiano Filaleto ligada, está, assim como na crítica à Descartes, à rejeição da ideia enquanto representativa de uma exterioridade:

Filaleto: Após ter examinado se as ideias são inatas, consideremos sua natureza e suas diferenças. Não é verdade que a ideia é o objeto do pensamento? Teófilo: Concordo, desde que acrescentais que é um $o b-$ jeto imediato interno, e que esse objeto é uma expressão da natureza ou das qualidades das coisas. [...] Os objetos sensíveis são mediatos, pois eles não podem agir imediatamente sobre a alma. Somente Deus é seu objeto externo imediato. (Id., GP v, p. 99)

Já comentamos a importância de Leibniz definir a ideia como um objeto e não como forma. Enquanto objeto, a ideia pode estar no entendimento por mais que pensamos nela presentemente ou não. Ora, se a ideia é um objeto imediato interno, isso significa que, enquanto representativa, ela não necessita de nenhum tipo de mediação para estar no entendimento. Em outras palavras, a ideia não é efeito, ela não necessita de nada exterior para existir na alma. $\mathrm{O}$ único objeto imediato externo da alma é Deus, que a cria e a mantém continuamente na existência. Ao mesmo tempo, "pode-se dizer que a própria alma é seu objeto imediato interno, enquanto ela contém as ideias, ou aquilo que corresponde às coisas" (Ibid.). Na medida em que as ideias são relações expressivas e, sendo assim, prescindem da relação modelo-original, elas constituem a alma enquanto um centro expressivo, que expressa o universo a partir de um ponto de vista particular. As ideias são constitutivas da alma e, enquanto objetos do pensamento, identificam-se com ela. O objeto do pensamento é simultaneamente as ideias que possuímos em nossa alma e a própria alma que possui essas ideias. ${ }^{5}$

Se todas as ideias são os objetos imediatos internos, o que significa dizer que os objetos sensíveis são mediatos? O sensível não pode agir diretamente sobre a alma e, portanto, não pode ser a causa de nossas ideias e nem o objeto imediato de nosso pensamento. O universo existe fora de nossa alma e só pode ser confusamente representado pelos sentidos. Ao contrário das ideias, o sensível não pode ser objeto do pensamento senão incitando a alma a ter certos pensamentos ao invés de outros: "a experiência é necessária, confesso, para que a alma seja determinada a tais ou tais pensamentos, e para que ela preste atenção às ideias que estão em nós" (Ibid., p. IOo). Os objetos sensíveis são mediatos, pois se limitam a nos dar

5 Ver Lacerda 2005, pp. I68-I70. 
a ocasião de pensar o que já se encontra em nós. Por meio deles somos levados a prestar atenção em determinadas ideias e não em outras, mas essas ideias estão necessariamente em nós. Não podemos falar da alma como uma faculdade nua, que só possui uma pura potência de receber impressóes do exterior, tal como uma tabuinha ou uma cera. Contra a ideia de uma tábula rasa, ou de uma alma vazia à espera de ser preenchida pelas ideias, Teófilo apresenta o oposto, a saber, uma alma que contém em si todas as ideias, sejam elas pensadas atualmente ou não:

Opor-me-ão esse axioma aceito entre os filósofos, que não há nada na alma que não vem dos sentidos. Mas é preciso excetuar a própria alma e suas afecções. Nibil est in intellectu, quod non fuerit in sensu, excipe: nisi ipse intellectus. [...] Isso está de acordo com o autor do Ensaio, que busca a fonte de uma boa parte das ideias na reflexão do espírito sobre sua própria natureza. (Ibid., p. Ioo)

A crítica de Leibniz a Locke perfaz assim um ciclo completo. Se o empirista criticava a concepção inatista das ideias por considerar que ela sujeitava o conhecimento à tradição e aos princípios imutáveis, Leibniz mostra que sua concepção de ideia inata não só está imune a essa crítica, como ainda pode ser demonstrada partindo do mesmo ponto de partida de Locke, a saber, a partir da reflexão sobre a natureza do espírito. Se isso não acontece, não é porque Leibniz assuma nos Novos Ensaios um ponto de partida empirista, mas sim porque nas objeções de Teófilo a própria noção de alma e de ideia se identificam a ponto de poder afirmar que "nós somos, por assim dizer, inatos a nós mesmos" (Ibid., p. 93). As ideias não se formam na alma como um efeito de algo que vem do exterior. Pelo contrário, elas constituem a alma ao expressar, a partir de si mesma, as relações que mantêm com todo o universo e com as verdades eternas.

Dizer que possuímos todas as ideias de forma inata em nós quer dizer, portanto, que possuímos em nossa alma todas as regras ou razóes pela qual a alma expressa todo o universo. Não como quadros inertes ao qual o entendimento se volta, nem como impressões causadas pelos nossos órgãos dos sentidos, as ideias estão em nós, isto sim, como virtualidades que, por mais que não cheguem à consciência, são marcas da relação que a alma trava com todo o universo. E, na medida em que essas virtualidades se tornam mais expressivas e mais distintas, elas se tornam parte do pensamento consciente.

\section{Filaleto, um cartesiano?}

A crítica que Leibniz faz à concepção empirista de ideia nos Novos Ensaios não se resume apenas à questão da sua origem. Ao apontar que as ideias expressam a 
natureza ou as qualidades da coisa, a crítica ao empirismo desdobra-se em crítica à própria noção da representatividade das ideias. Assim como com Descartes, a formulação de uma noção de representação que se regula por uma relação de ordem em vez de uma relação de semelhança imitativa é, ao lado do inatismo, o ponto fundamental da discórdia entre esses filósofos, no que diz respeito às ideias. Mas, dado que Descartes e Locke possuem concepções bastante diferentes, e por vezes radicalmente opostas, de ideias — principalmente no que diz respeito à relação delas com o sensível —, como é possível que Leibniz afirme que ambos cometem o mesmo erro, a ponto de dizer que Locke concede demais aos cartesianos?

No livro II do Ensaio sobre o entendimento humano, Locke distingue as qualidades percebidas no objeto em qualidades primárias e qualidades secundárias. Qualidades primárias são aquelas "absolutamente inseparáveis do corpo, seja qual for o estado em que ele esteja" (Locke 1979, p. 134). Qualidades secundárias, por sua vez, são as "que não são nada, nos próprios objetos, mas poderes [powers] de produzir várias sensações em nós por suas qualidades primárias” (Ibid., p. I35). Qualidades primárias resumem-se a solidez, extensão, figura, movimento ou repouso, e número; as secundárias ou sensíveis, por sua vez, são as cores, sabores, sons, etc. Apenas a percepção das qualidades primárias pode ser considerada semelhante aos corpos percebidos, pois elas são permanecem nos objetos independentemente de nossa percepção deles. A percepção das qualidades secundárias, por sua vez, é arbitrária, pois só possuem uma existência objetiva na medida em que são sensações em nós, e não enquanto propriedades intrínsecas do objeto.

Teófilo, ao comentar essa distinção lockiana, tal como exposta por Filaleto, não a recusa de imediato. Entretanto, a distinção entre ambas as classes de qualidades não é, para ele, de natureza:

Creio que se poderia dizer que quando a potência [dos corpos de produzir sensações em nós] é inteligível e pode ser explicada distintamente, ela deve ser contada entre as qualidades primárias; mas, quando é meramente sensível, e fornece apenas uma ideia confusa, deve ser colocada entre as qualidades secundárias. (Leibniz, Id., pp. II7-II8).

Apesar de manter a terminologia de Locke e aceitar em certo sentido a distinção entre as qualidades primárias e as qualidades secundárias, Leibniz, ao deslocar essa questão para o grau de distinção das ideias, recusa não a distinção em si, mas sim a distinção de natureza entre uma classe e outra. Na doutrina leibniziana das ideias, há, entre as ideias distintas e as ideia confusas, uma continuidade, marcada pelo grau de distinção da expressão das ideias. Entre uma ideia e outra não há uma diferença de natureza, apenas uma distinção do quanto podemos conhecer a 
respeito de um dado objeto. E, enquanto as ideias que nos representam as coisas inteligíveis podem atingir um grau maior de distinção, as das coisas sensíveis serão sempre confusas, em virtude da própria natureza da sensação.

Dizer que as qualidades primárias podem ser distintamente conhecidas e são inteligíveis implica dizer, portanto, que elas são suscetíveis de serem tratadas através dos conhecimentos distintos e inteligíveis da física. A solidez, o número, a figura e o movimento mostram como os corpos interagem entre si e atuam uns sobre os outros, de modo que, enquanto dependentes de regras e leis que podem ser estabelecidas de uma maneira distinta, elas são, por sua vez, o objeto de ideias distintas. Em outras palavras, essas qualidades podem ser reduzidas a conceitos distintos pois, enquanto tais, independem da experiência sensível que possuímos deles.

Qualidades secundárias ou sensíveis, por outro lado, só podem ser concebidas enquanto tais na medida em que são percebidas pelos órgãos sensíveis. Ao serem formadas por elementos percebidos confusamente, elas não são, enquanto dependentes das ideias confusas da sensação, passíveis do mesmo conhecimento distinto que as qualidades primárias. Entretanto, isso não implica afirmar que essas qualidades sensíveis e as suas representações sejam, como afirma Locke, arbitrárias em relação aos movimentos que as geram.

Não se deve imaginar que essas ideias como as de cor ou dor sejam arbitrárias e não tenham relação ou conexão natural com as suas causas: não é costume de Deus agir com tão pouca razão. Eu diria, em vez disso, que há uma espécie de semelhança, não completa, e, por assim dizer, in terminis, mas expressiva, ou de relação de ordem, como uma elipse e mesmo uma parábola ou hipérbole se assemelham de algum modo com ao círculo do qual são a projeção no plano, pois há uma certa relação, exata e natural, entre o que é projetado e a projeção que é feita, cada ponto de um tendo certa relação com cada ponto do outro. (Ibid., p. II8)

Essa espécie de semelhança a que Leibniz se refere é justamente a relação regrada que caracteriza as relações expressivas. Essa noção expandida de semelhança não a relaciona com a semelhança imitativa, ou in terminis (traço por traço), mas sim uma regra comum, que possa relacionar um e outro. Deslocando assim a marca da semelhança, Leibniz pode afirmar que a elipse, a parábola e a hipérbole se assemelham ao círculo do qual elas são a projeção no plano, pois cada ponto do círculo corresponde, por uma lei exata, a cada ponto das figuras formadas - por mais que entre essas três figuras e o círculo não haja nenhuma imagem em comum. O exemplo extraído das secçōes cônicas é significativo, pois as diferentes 
figuras formadas pela secção do cone que é projetado em um círculo podem ser relacionadas entre si a partir das relaçóes estabelecidas entre cada ponto da figura e cada ponto do círculo, e não a partir de uma definição comum ou de um elemento originário. A parábola não é semelhante ao círculo por se originar dele, nem o contrário. Assim, é compreensível que Leibniz se valha aqui do mesmo exemplo das secções cônicas que utiliza ao explicar a Arnauld o que ele entende por expressão. Essas figuras são semelhantes entre si por possuírem uma relação de ordem, ou seja, por constituírem uma relação expressiva. Por isso, escreve Leibniz a Foucher, "não é necessário que o que nós concebemos das coisas fora de nós lhes seja perfeitamente semelhante, mas que as exprima, como uma elipse exprime um círculo visto de lado, de modo que cada ponto do círculo corresponda a um da elipse e vice-versa, seguindo uma certa lei de relação". (Id., A II, 2, pp. 90-9I) Desse modo, as qualidades sensíveis podem ser consideradas semelhantes aos movimentos que as causam, por mais que não haja nenhum tipo de semelhança imediata ou evidente. A dificuldade em se encontrar uma relação direta entre o movimento que as causa e a ideia que possuímos dela se deve somente à confusão que envolve a sua representação. A representação de uma multiplicidade confusamente percebida não permite que encontremos em cada um dos elementos o modo pelo qual eles se relacionam com a ideia dessas qualidades. Mas, conhecendo as leis gerais que regem as relaçôes, podemos dizer com certeza que cada sensação corresponde perfeitamente aos elementos presentes nos movimentos que os causam e, portanto, pode-se dizer que se assemelham a eles do mesmo modo que as qualidades primeiras os fazem. O caráter evidente da semelhança se perde nas partes mínimas que compõem a representação. "É verdade que a dor não se assemelha ao movimento de um alfinete [na carne], mas ela pode muito bem se assemelhar aos movimentos que esse alfinete causa em nosso corpo e representar esses movimentos na alma, como eu não duvido que ela faça”" (Id., GP v, p. II9). Ser semelhante, no sentido aqui exposto, implica uma expressão entre dois elementos aparentemente distintos.

É nesse ponto que a crítica que Leibniz faz a Locke nos Novos Ensaios não só se desdobra em uma crítica a Descartes e ao cartesianismo, como ainda mostra como ambos os filósofos, possuindo concepções quase opostas sobre as ideias, acabam por concordar no que diz respeito ao conteúdo representativo das ideias sensíveis. Tanto para um quanto para o outro, as ideias só podem ser consideradas representativas de algo quando há uma relação clara e intuitiva entre o que é representado e a representação que se forma em nossa alma. As qualidades sensíveis, por não serem redutíveis às representações dos elementos fundamentais e inteligíveis da extensão, encontram-se fadadas a não se assemelhar a nada de exterior. Para 
Locke, as qualidades sensíveis que recebemos pelos sentidos não tem nenhuma relação com os movimentos da matéria que percebemos sensivelmente. Para Descartes, apenas as ideias claras e distintas, que não possuem nenhuma relação com os sentidos, representam algo objetivamente. O sensível é para o último o produto da união substancial entre a alma e o corpo, e não transmite nenhum conteúdo objetivo ao intelecto. Embora o percurso cartesiano e o empirista sejam distintos, ambos atribuem à semelhança intuitiva o modelo fundamental para as suas concepções de ideia, e encontram no sensível o limite desse modelo.

Embora de modos diferentes, tanto o francês quanto o inglês encontram sua concepção de ideia no modelo cópia-original. A ideia é para ambos representativa na medida em que ela reproduz a coisa percebida no entendimento, Locke enquanto uma imagem dos sentidos, Descartes enquanto uma imagem inerte na alma. Por isso, ao comentar a distinção entre ideias das qualidades primeiras e ideias das qualidades segundas, Teófilo diz que Filaleto concedeu demais aos cartesianos (Ibid., p. II8). O empirismo vai ao encontro do cartesianismo ao conceber a ideia como a apresentação de algo à mente, como cópia de algo cujo original se encontra alhures.

É justamente a essa noção estreita de semelhança que a ideia expressiva leibniziana se opõe. Ao afirmar que o caráter representativo da ideia não depende de uma semelhança intuitivamente percebida, mas sim de uma relação regrada entre um elemento e outro, de um invariante que permanece na variação dos elementos, Leibniz pode recolocar o problema do caráter representativo da ideia em outros termos, a saber, em termos propriamente expressivos. A representação não implica cópia, transmissão ou imitação, mas sim relação. $\mathrm{O}$ universo é representado na unidade da substância porque a substância contém em si as regras pela qual ela se relaciona, a partir de seu ponto de vista, com todo o universo.

A ideia deixa de ser assim a representação de uma exterioridade para se tornar uma lei de correspondência, cuja razão se encontra na própria alma. Perceber não é receber na alma algo de exterior nem ter no interior da alma algo que se assemelha ao que há no exterior, apenas possuir na alma as correspondências entre ela e todas as outras substâncias criadas. O que Leibniz coloca em jogo, como já vimos, é a própria relação entre interioridade e exterioridade, no que diz respeito à percepção. Em um opúsculo em que comenta as críticas de Locke à filosofia de Malebranche, Leibniz escreve: "O padre, ao dizer que as ideias são seres representativos, dá ensejo ao senhor Locke perguntar se esses seres são substâncias, modos ou relaçôes. Creio que são meras conexões [rapports], que resultam dos atributos de Deus" (Id., GP VI, p. 576). 


\section{A imagem sem original}

Não há portanto percepção de algo que está além da alma, apenas de algo que já se encontra nela de forma inata. Percebemos a todo o momento o universo inteiro, pois temos em nossa alma as regras das relações que ligam a nossa alma com o todo e com cada substância individual ou mônada. A substância "é como um mundo à parte, independente de qualquer outra coisa, excetuando-se Deus" (Id., A VI, 4, p. I554), pois todas as relações que ela trava com o universo inteiro dependem apenas de si mesma. Mas, embora a percepção de cada substância só dependa dela mesma, a harmonia preestabelecida entre as substâncias garante que todas as suas expressōes e suas respectivas expressōes nas outras substâncias se organizem de modo que ambos se acomodem entre si do modo mais perfeito possível, de modo que todas as substâncias se expressem umas às outras harmonicamente. É ela então que garante que as relações expressivas da alma não caiam no solipsismo, que as ideias se encontrem no interior de um modelo inteligível no qual suas expressões tenham correspondência mútua com todas as outras no universo. Assim, a concepção da substância como um centro expressivo se sustenta na teoria da harmonia preestabelecida, e, através dela, garante que a expressão no interior da substância corresponda a uma expressão mútua da totalidade das substâncias criadas. Ou, como explica Leibniz a Des Bosses:

É verdade que as coisas que acontecem na alma devem concordar com as que acontecem fora da alma; mas, para isso, é suficiente que essas coisas que acontecem em uma alma correspondam tanto entre si quanto com coisas que se passam em qualquer outra alma, não é necessário postular algo além das almas ou mônadas. De acordo com essa hipótese, quando dizemos que Sócrates está sentado, isso significa somente que essas coisas que entendemos por Sócrates e sentado aparecem para nós e para os outros. (Id., GP II, pp. 45I-452)

Mas, se é assim, por que então frequentemente consideramos que o que representamos em nós está efetivamente fora de nós e tem sua imagem impressa ou reproduzida em nossa mente? Segundo Teófilo, isso ocorre porque caímos em um erro similar àquele em que incorremos quando a regra da perspectiva é bem

aplicada por um pintor. É possível traçar desenhos planos e sem sombreados, se o que se quer é representar coisas planas, como, por exemplo, um círculo sem relevo, ou desenhar medalhas ou ainda realizar desenhos à moda dos chineses. Mas não podemos distinguir no desenho uma esfera de um círculo sem a ajuda de sombras, pois não há entre eles pontos nem traços distintos. É isso que levou 
Desargues, ao expor sua análise da perspectiva, a dar preceitos sobre uso de tintas e de sombras. ${ }^{6}$ Assim, quando uma pintura nos engana, há um duplo erro em nossos juízos:

Em primeiro lugar, trocamos a causa pelo efeito, crendo ver imediatamente o que é a causa da imagem, e, fazendo assim, agimos um pouco como um cachorro que late contra o espelho; pois tudo o que vemos, propriamente dizendo, é a imagem, e somos afetados apenas pelos raios. [...] Em segundo lugar, nos enganamos novamente, quando trocamos uma causa por outra e cremos que o que vem de uma pintura plana é derivado de um corpo, de tal modo que nesse caso há, em nosso juízo, ao mesmo tempo, uma metonímia e uma metáfora; pois mesmo as figuras de retórica passam por sofismas, quando abusam de nós. (Id., GP v, p. I22)

A comparação com as figuras de retórica evidencia como, para Leibniz, a imagem pintada em perspectiva cria em nós a ilusão de estar lidando com objetos exteriores. A metonímia implica uma relação de contiguidade entre termos, e a metáfora cria semelhanças entre termos distintos: ambas são sofismas, na medida em que nos fazem acreditar em semelhanças e causalidades que não se encontram realmente nas coisas representadas, como imaginar que vemos imediatamente o quadro, e não a sua representação ou ideia, ou que o que está representado na pintura plana é realmente o corpo. Por isso, julgamos haver um efetivo comércio entre alma e corpo, quando, na verdade, um expressa o que ocorre no outro.

É interessante notar que os exemplos levantados para comentar esse duplo erro se referem a dois usos distintos da perspectiva. Em primeiro lugar, a perspectiva aplicada à ótica e aos raios de luz que atingem nossos olhos dá o exemplo da metonímia, que nos faz tomar a causa pelo efeito. Em segundo, a perspectiva aplicada à pintura se relaciona à metáfora ao gerar a percepção de um objeto onde não há senão tinta em uma tela plana. Em ambos os casos, as regras da representação, enquanto dependentes da perspectiva, são as mesmas, embora em um caso se trate das leis da óptica e, no outro, da perspectiva enquanto artifício pictórico. As representações, por exemplo, de uma esfera pintada segundo as regras da perspectiva, e da esfera pintada em nossa retina na visão, não diferem em gênero, uma não é menos representativa do que a outra. A perspectiva, por

6 Leibniz, assim como outros em sua época, considerava a teoria das sombras uma variante da perspectiva: "A doutrina das sombras nada mais é que uma perspectiva invertida e resulta dela mesma quando se póe o luzente no lugar do olho, o opaco no lugar do objeto e a sombra no lugar da projeção". (Nouveaux essais, G vII, pp. I69-I70). 
estabelecer uma relação regrada entre elementos distintos (o círculo sombreado e a esfera, o quadro no espaço e o quadro pintado em nossa retina) é o que garante, nos dois casos, a existência de uma relação expressiva, tornando-os, portanto, efetivamente representativos. Em ambos, o erro se deve somente ao julgamento, que considera haver nas imagens algo para além da representação. Por mais que a esfera pintada possa não existir efetivamente, tampouco podemos garantir a existência do quadro, pois "como os raios de luz necessitam de tempo (por menor que seja) é possível que o objeto seja destruído nesse intervalo e não subsista mais quando o raio atinge o olho, e o que não é mais não pode ser o objeto presente da visão". (Ibid.) Em um caso como no outro, tudo o que percebemos são as leis das relações expressivas que se encontram unicamente em nós.

Leibniz pensa que Descartes e Locke incorrem nesse mesmo erro, ao afirmar que a representação é a imitação de algo que se encontra alhures, quando representar é encontrar uma regra comum, um invariante, uma relação expressiva entre os elementos. Ora, a perspectiva é justamente uma regra que relaciona os elementos distintos (imagem, raios, pintura plana, imagem pintada, objeto representado pela pintura) a partir das regras claras da geometria projetiva. $\mathrm{O}$ engano que equipara as posiçôes do lockiano Filaleto e as de Descartes é achar que há algo para além da relação, um original que precede a representação. A concepção leibniziana de representação busca justamente superar esse modelo, para ressaltar que a representação não se dá de um polo a outro, mas unicamente na própria relação expressiva entre eles. Se a mônada é um espelho do universo, ela não o é por refletir com uma imagem fiel o que está diante dela, mas por ter em si as imagens, nem sempre perfeitamente reconhecíveis, de tudo que se encontra no universo.

\section{Referências bibliográficas}

Descartes, R. Oeuvres de Descartes. Ed. Adams \& Tannery. Paris: Vrin, i97I.

Lacerda, T. M. A politica da metafísica. São Paulo: Humanitas, 2005.

Leibniz, G. W. Die philosophischen Schriften. Herausgegeben von C. I. Gerhardt. Berlin: Weidmann, I875-85. Opuscules et fragments inédits. Org. Couturat, L. Paris: Félix Alcan, 1903.

. Sämtliche Schriften und Briefe. Herausg. von der Berlin Brandenburgischen Akademie der Wissenschaften und der Akademie der Wissenschaften in Göttingen. Berlin und Göttingen: Akademie Verlag, 1966-2015.

Locke, J. An Essay Concerning Human Understanding. Ed. Nidditch. Oxford: University Press, 1979.

Serres, M. Le Système de Leibniz et ses Modèles Mathématiques. Paris: puf, $200 \mathrm{I}$. 